\title{
The UK-NEA Papers: Introduction
}

\section{Partha Dasgupta}

Accepted: 9 April 2013 / Published online: 27 September 2013

(C) Springer Science+Business Media Dordrecht 2013

National economic accounts are descriptors. They describe the state of an economy and form the raw material for both assessing its performance and prescribing policy. National accounts embody information that is essential for economic evaluation.

The framework for national accounts currently in use throughout the world, however, suffers from extreme narrowness. Vast quantities of information relevant for economic evaluation do not appear in them. Some don't because the appropriate data are hard, even impossible, to collect; but others don't because the theory and practice of economic evaluation haven't ask for them. The widespread demand for green accounts has arisen in recent years because of a growing recognition that contemporary national accounts are an unsatisfactory basis for economic evaluation. The qualifier "green" signals that we should be especially concerned about the absence of information on society's use of the natural environment. ${ }^{1}$

1 In 2011 the Government of India convened an Expert Group for the task of preparing a report on Greening India's National Accounts. The Group's draft report is due for submission in April 2013.

Ian Bateman's appointment to the Order of the British Empire by Her Majesty Queen Elizabeth II in the 2013 New Year Honours List is an altogether fitting tribute to an economist who has almost single-handedly lifted the economics of ecosystem services from case-studies to the mapping and valuation of overarching natural systems. Our Association recognizes too that Ian has served and continues to serve as a remarkable editor of its journal, repeatedly encouraging the publication of Special Issues on themes that are significant for being both salient for an understanding of the processes that shape Human-Nature interchanges and neglected in mainstream environmental and resource economics. For some years many of us had become aware that Ian was helping to frame the economics of the United Kingdom's monumental National Ecosystem Assessment (UK-NEA). That is why in 2011, as President of EAERE I suggested to him that he should submit a collection of articles from that work to our Association's journal and instructed him to invite me to serve as Guest Editor. The findings in this Special Issue are a testament to the zeal and abilities of an outstanding research scientist and intellectual leader.

P. Dasgupta $(\varangle)$

St John's College, Cambridge, UK

e-mail: partha.dasgupta@econ.cam.ac.uk

P. Dasgupta

Sustainable Consumption Institute, University of Manchester, Manchester, UK 


\section{National Wealth}

In recent years economists have developed a comprehensive theory of national accounts based on primary ethical principles. Attempts have also been made to put the theory to work on national and international data. The theory takes as its starting point the view that the ultimate purpose of economic evaluation is the protection and promotion of well-being across the generations. It instructs governments and international agencies to go beyond even green national accounts by reclassifying certain classes of goods and services and adding others that are currently missing. The theory goes on to show that the object of economic evaluation should be a comprehensive notion of wealth (adjusted for population and the distribution of wealth in the economy), not gross domestic product (GDP) nor the many other ad hoc indicators of human well-being that have been advanced in recent years, such as the United Nations' Human Development Index. ${ }^{2}$

The theory is even more specific. It says that under a wide range of conditions, changes in the circumstances of an economy should be judged on the basis of their effect on the economy's wealth per capita, adjusted for the distribution of wealth. A corollary is that net investment per capita should be the object of interest in flow accounts, not per capita gross investment.

Wealth is the social value of an economy's stock of capital assets, comprising (1) produced capital (commonly known as "manufactured capital"), (2) human capital (the size and composition of population, education, and health), and (3) natural capital (e.g., ecosystems, sub-soil resources). To be sure, the notion of "capital assets" extends today to institutions, knowledge, culture, religion, and even norms and practices. The theory acknowledges that those intangible objects are indeed assets, but instructs that they should be regarded as the "social infrastructure" within which the more grounded capital assets [categories (1)-(3)] get allocated and are put to use.

The objects that link capital assets [categories (1)-(3)] and well-being across the generations are shadow prices, which are the social worth of capital assets. The social infrastructure just alluded to is a factor determining shadow prices. As wealth is a stock, the theory tells us that particular attention should be paid to an economy's capital accounts. That suggests there should be a shift in interest within flow accounts from gross to net investment, the latter being the value of the change in the quantity (or quality) of capital assets. ${ }^{3}$

\section{What is Investment?}

The word "investment" could be thought to embody a sense of robust activism. But that's only because national income statisticians have traditionally limited the term's use to the accumulation of produced capital. When the government invests in roads, the picture that's drawn is one of bulldozers levelling the ground and tarmac being laid by men in hard hats. By widening the range of capital assets to include health, education, and natural capital, the theory I am recounting here extends the notion of capital. So we are obliged to stretch the

\footnotetext{
2 See Hamilton and Clemens (1999), Dasgupta and Mäler (2000), Arrow et al. (2003, 2004, 2012a,b), Dasgupta (2004, 2009), and UNU-IHDP/UNEP (2012).

3 The theory shows that even the previous sentence in the text requires explanation: Let $L(t)$ denote population size at date $t, K_{i}(t)$ the stock of capital asset $i$, and $P_{i}(t)$ the asset's shadow price. Wealth, $W(t)$, is then $W(t)={ }_{i} \sum P_{i}(t) K_{i}(t)$ and wealth per capita is $W(t) / L(t)={ }_{i} \sum P_{i}(t) K_{i}(t) / L(t)$. Let $k_{i}(t)=K_{i}(t) / L(t)$ and $p_{i}(t)$ the corresponding shadow price. The theory says that "net investment per capita" should be taken to mean ${ }_{i} \sum p_{i}(t) \mathrm{d} k_{i}(t) / \mathrm{d} t$; it should not be interpreted to mean $\left[{ }_{i} \sum P_{i}(t) \mathrm{d} K_{i}(t) / \mathrm{d} t\right] / L(t)$.
} 
notion of "investment" also, which now includes the growth of renewable natural resources such as ecosystems. To leave a forest unmolested so as to enable it to grow would in our extended sense be to invest in the forest. To allow a fishery to restock under natural conditions would be to invest in the fishery.

That suggests investment amounts to deferred consumption, but the matter is subtler. To provide food to the undernourished not only increases their current well-being, it enables them also to be more productive in the future. The latter feature makes even consumption among the poor an investment. Investment is therefore any decision that enhances future consumption. No doubt that sounds odd, but theory and empirics taken together should determine our usage of technical terms, not preconception nor customary usage.

It is a simple matter to prove that the shadow price of an asset is the present discounted value of the change in present and future consumption an additional unit of the asset would make possible. So, by "net investment" in an asset we should mean the value of the rate of change in the stock of the asset.

\section{Natural Capital}

This Special Issue is on the valuation of ecosystem services. So it is as well first to recount the value of natural capital. Natural capital is of direct use in consumption (fisheries), of indirect use as inputs in production (oil and natural gas; the wide array of ecosystem services), and of use in both (air and water). The value of a resource may be utilitarian (as a source of food, or as a keystone species) — many people call this its use-value; it may be aesthetic (places of scenic beauty), or it may be intrinsic (primates). And it may be all these things (biodiversity). Their worth to us could be from extraction (timber, gum, honey, leaves and barks) or from their presence as a stock (forest cover), or from both (watershed). The stock could be an index of quality (air quality) or quantity. Quantity is sometimes expressed as a pure number (population size); in various other cases it is, respectively, (bio)mass, area, volume, depth. But even quality indices are often based on quantity indices, as in "parts per cubic centimetres" for measuring atmospheric haze.

An ecosystem is a complex of the abiotic environment and plant, animal, fungi, and microorganism communities, interacting as a functional unit. Aside from fisheries and forests as sources of timber, ecosystems have traditionally been neglected by economists and national income accountants; to everyone's loss, because ecosystems provide innumerable services to us. Among the visible products are food, fibres, fuel, and fresh water; but many remain hidden from view. Among other things, ecosystems maintain a genetic library, preserve and regenerate soil, fix nitrogen and carbon, recycle nutrients, control floods, mitigate droughts, filter pollutants, assimilate waste, pollinate crops, operate the hydrological cycle, and maintain the gaseous composition of the atmosphere. As those services are not visible, it is easy to overlook them. However, with ingenuity it is possible to estimate the benefits we enjoy from them. The articles in this Special Issue illustrate how. ${ }^{4}$

Ecosystems offer joint products. Wetlands recycle nutrients and produce purified water, mangrove forests protect coastal land from storms and are spawning grounds for fish, and so on. Unhappily, social tensions arise in those many cases where an ecosystem has competing uses (farms versus forests versus urban development; forests versus agro-ecosystems; coastal fisheries versus aquaculture). As natural capital is a mesh of resources, what one means by

4 Millennium Ecosystem Assessment (MEA) (2005a,b,c,d), Balmford et al. (2011), and Bateman et al. (2011) are precursors and contain excellent accounts of the role ecosystems play in economic life. 
an ecosystem is usually influenced by the scope of the problem being studied. A number of ecosystems have a near global reach ("biomes", such as the Savannah), some cover entire regions (river basins), many involve clusters of villages (micro-watersheds), while others are confined to the level of a single village (the village pond). The tropics harbour some of the most fragile environments.

Environmental pollutants are the reverse of natural resources. In some cases the emission of pollutants amounts directly to the depreciation of produced capital (corrosion of material infrastructure). In others it means a degradation of ecosystems (eutrophication of lakes). Roughly speaking "resources" are "goods", many being sinks into which pollutants are discharged (rivers, the atmosphere, and the oceans are among the sinks); while "pollutants" (the degrader of resources) are "bads". Pollution is the other side of conservation. ${ }^{5}$

In a far reaching publication, Millennium Ecosystem Assessment (MEA) (2005a,b,c,d) reported on the state of the world's ecosystems. The authors created a four-way classification of ecosystem services: (1) provisioning services (food, fibre, fuel, fresh water); (2) regulating services (protection against natural hazards such as storms; the climate system); (3) supporting services (nutrient cycling, soil production); and (4) cultural services (recreation, cultural landscapes, aesthetic or spiritual experiences). The classification is particularly useful for reaching an understanding of the natural-capital base of an island economy. That is why the authors in this Special Issue adopted it.

Provisioning and cultural services and a variety of regulating services (e.g., disease regulation) contribute directly to human well-being, whereas supporting services (soil production), contribute indirectly (by providing the means of growing food crops). As those services are frequently in competition with one another, choices have to be made. The long history of agriculture is one where ecosystems were transformed from supplying regulating and supporting services to supplying provisioning services, a matter that is stressed in UK-NEA's account of the changing landscape in the British Isles. Equally familiar to us today is the process by which ecosystems are being destroyed for industrialization and urbanization.

\section{Estimating Shadow Prices}

Three pieces of information are required for estimating shadow prices:

1. A descriptive model of the economy moving through time, including not only technological possibilities and ecological processes, but also preferences, tastes, personal and social values, and policies.

2. The size and distribution of the economy's capital assets at the date at which the economic evaluation is undertaken.

3. A conception of social well-being.

There should be no presumption that the economy is on an optimum trajectory. The prices ought to be estimated on the basis of the evaluator's economic forecast, which could, for example, be based on an integrated assessment model of the economy. In their valuation of urban green space in Britain, Perino et al. in this Special Issue follow the above three steps.

Estimating shadow prices is not for the weak minded. It is all well and good to regard the estimation process as consisting of three steps, but each step is full of difficulties. Corners have to be cut, and they can be guaranteed to generate controversy. Market prices, where they exist, would appear to be the first port of call. Even when they don't exist, as is often the

5 This classification was explored in Dasgupta (1982). 
case with provisioning services, market prices are often the yardstick with which to judge the social worth of the final product (e.g., agricultural crops; as in the article by Fezzi et al. in this Special Issue).

The gap between market and shadow prices of ecosystems reflect externalities, which are the unaccounted for consequences for others (including future people) of actions taken by each of us. Formally, if $R_{i}(t)$ is the market price of asset $i$ at $t, E_{i}(t)$ is the social value of the externalities generated by $i$ 's use at $t$, and $P_{i}(t)$ is the shadow price of $i$ at $t$, then

$$
P_{i}(t)=R_{i}(t)+E_{i}(t) .
$$

In Eq. (1) $E_{i}(t)$ embodies the externalities generated by $i$ at $t$ over the future. To cite an example of much current interest, consider that a further addition to the stock of carbon in the atmosphere today will have effects (the externalities) lasting many years. If asset $K_{i}(t)$ denotes the stock of carbon in the atmosphere at time $t, E_{i}(t)$ would reflect those effects. If increased concentration of carbon in the atmosphere is predicted to be bad for the economy in question, $E_{i}(t)<0$. If carbon emissions are not taxed, $R_{i}(t)=0$. In that case $P_{i}(t)=E_{i}(t)<0$.

Frequent short cuts to estimating shadow prices involve asking people to say how much they value the assets in question ("stated preference"), or alternatively, inferring them from what they do ("revealed preference"; Gibbons, Mourato, and Resende in this Special Issue). They are short cuts in as much as the evaluator avoids steps (1) and (2) by assuming that the subjects have done the work themselves. They are short cuts also because step (3) is simplified by an identification of intergenerational well-being with people's preferences.

The contributors to this Special Issue have adopted valuation methods that would seem most suited for the ecosystem services they study. I can imagine experts will quibble over details. However, what they will not quibble over is the significance of the articles in this Special Issue and the boldness with which the investigators have gone about their work. The final paper in the collection, by Bateman et al. is a masterly summary of the economics underlying the UK National Ecosystem Assessment. It provides an outline of an enormously promising and important research agenda.

\section{References}

Arrow KJ, Dasgupta P, Goulder L, Daily G, Ehrlich PR, Heal GM, Levin S, Mäler K-G, Schneider S, Starrett DA, Walker B (2004) Are we consuming too much? J Econ Perspect 18(1):147-172

Arrow KJ, Dasgupta P, Goulder LH, Mumford K, Oleson K (2012a) Sustainability and the measurement of wealth. Environ Dev Econ 17(3):317-353

Arrow KJ, Dasgupta P, Goulder LH, Mumford K, Oleson K (2012b) Sustainability and the measurement of wealth: further considerations. Environ Dev Econ, forthcoming, 2013

Arrow KJ, Dasgupta P, Mäler K-G (2003) The genuine savings criterion and the value of population. Econ Theory 21(2):217-225

Balmford A, Fisher B, Green RE, Naidoo R, Strassburg B, Kerry Turner R, Rodrigues ASL (2011) Bringing ecosystem services into the real world: an operational framework for assessing the economic consequences of losing wild nature. Environ Resour Econ 84(2):161-175

Bateman IJ, Mace GM, Fezzi C, Atkinson G, Turner K (2011) Economic analysis of ecosystem service assessments. Environ Resour Econ 84(2):177-218

Dasgupta P (1982) The control of resources. Harvard University Press, Cambridge

Dasgupta P (2004) Human well-being and the natural environment, 2nd edn. Oxford University Press, Oxford

Dasgupta P (2009) The welfare economic theory of green national accounts. Environ Resour Econ 42(1):3-38

Dasgupta P, Mäler K-G (2000) Net national product, wealth, and social well-being. Environ Dev Econ 5(1):69-93 
Hamilton K, Clemens M (1999) Genuine savings rates in developing countries. World Bank Econ Rev 13(2):333-356

Assessment Millennium Ecosystem (MEA), Hassan R, Scholes R, Ash N (eds) (2005a) Ecosystems and human well-being, I: current state and trends. Island Press, Washington

Assessment Millennium Ecosystem (MEA), Carpenter SR, Pingali PL, Bennet EM, Zurek MB (eds) (2005b) Ecosystems and human well-being, II: scenarios. Island Press, Washington

Millennium Ecosystem Assessment (MEA), Chopra K, Leemans R, Kumar P, Simmons H (2005c) Ecosystems and human well-being, III: policy responses. Island Press, Washington

Assessment Millennium Ecosystem (MEA), Capistrano D, Samper CK, Lee MJ, Randsepp-Hearne C (eds) (2005d) Ecosystems and human well-being, IV: multiscale assessments. Island Press, Washington

UNU-IHDP/UNEP (2012) Inclusive wealth report 2012: measuring progress toward sustainability. Cambridge University Press, Cambridge 